\title{
A Call to Action
}

\section{Alwyn Eades}

Emeritus Professor of Materials Science and Engineering, Lehigh University, Bethlehem, PA 18015

jae5@lehigh.edu

\section{We have to do better}

In the July 2015 issue of Microscopy Today, I issued a challenge to microscopists to improve the way microscopy-related topics appear in Wikipedia. Here I renew that challenge. (In fact there were two challenges: more on the other one below.) I have recently (April 2017) taken another look at some Wikipedia entries in our field, and the situation seems very much unchanged.

To much of the world and to many students, Wikipedia is the first and only place from which they obtain information on technical matters. If we wish to create a favorable impression of our field - and surely we do-we need good Wikipedia entries on all the topics that a member of the general public might inquire about.

It is still the case that the entry for the Microscopy Society of America (MSA) is a paltry four and a half lines and that the International Federation of Societies for Microscopy (IFSM) has no entry at all. Compare, for example, the entry for the American Physical Society with that for the Microscopy Society of America.

Things are also horrendous on many of the microscopy and microanalysis topics I checked. The entry on "raster scan" makes no mention of any form of microscopy. The entry on "secondary electrons" refers to SEM only as an afterthought. The entry on "scanning electron microscope" has a link to "back-scattered electrons" but if you follow that link you get to a site ("backscatter"), which makes no mention of any form of microscopy.

I believe that a good Wikipedia entry on a science topic should have an opening paragraph that explains the general idea at a level that can be understood by, say, a middle-school studentand then go into more technical detail in subsequent paragraphs. For example, the entry on "scanning tunneling microscope" starts in a confusing and overly technical way, whereas the first sentence of the entry on "scanning probe microscopy" is much better, though even there more information at a general level might be good before going into detail.

I am feeling desperate about this. What is the point of all the wonderful work we do if we do not communicate it to the world? I am getting old and do not have the computer savvy of younger generations. So it is with some trepidation that I make the following suggestion. Will those of you who use "social media" (as I do not) set up a virtual community or a network of microscopists who will collaborate on identifying topics where the entries are absent or inadequate - and then get them written? Many of us give classes and visit schools to talk about the things we do. It cannot be much extra work to put it into "Wikipedia speak" and load it.

\section{We must do better} right.

Please, please, please, consider how you can help to put this

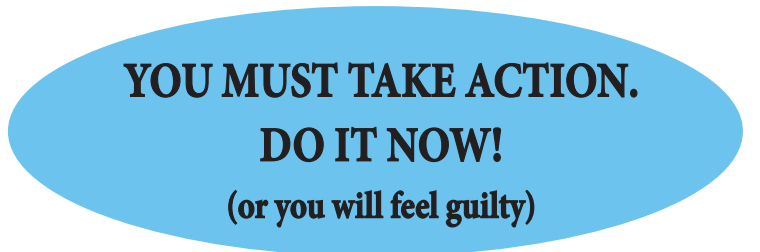

The second challenge was to write a limerick about Wikipedia. That competition was won by Jacquelyn Beals with this entry:

Wikipedia holds far more knowledge

Than one ever encounters in college.

End to end, all their files

Stretch for light years, not miles

(Which Britannica hates to acknowledge).

Congratulations to Jackie. Our apologies for such a long delay in awarding the prize.

\section{New! $70 \mathrm{~mm}^{2}$ and $25 \mathrm{~mm}^{2}$ FAST SDD for} EDS (SEM) Applications

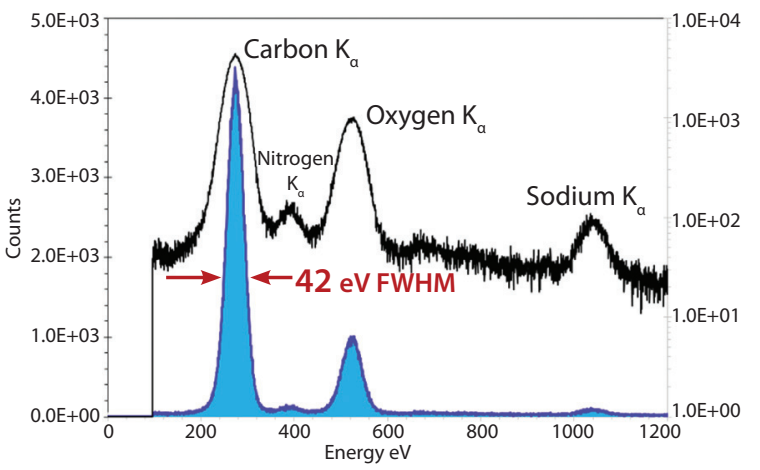

Amptek's new FAST SDD ${ }^{\circledR}$ detectors for EDS use with SEMs utilize "C2 Series" X-ray windows $\left(\mathrm{Si}_{3} \mathrm{~N}_{4}\right)$ and have excellent low energy response. Its high intrinsic efficiency makes it ideal for EDX, XEDS, EDXA and EDXMA. See why Amptek detectors are the \#1 choice of OEMs worldwide.

\section{OEM's \# 1 Choice}

\section{www.amptek.com}




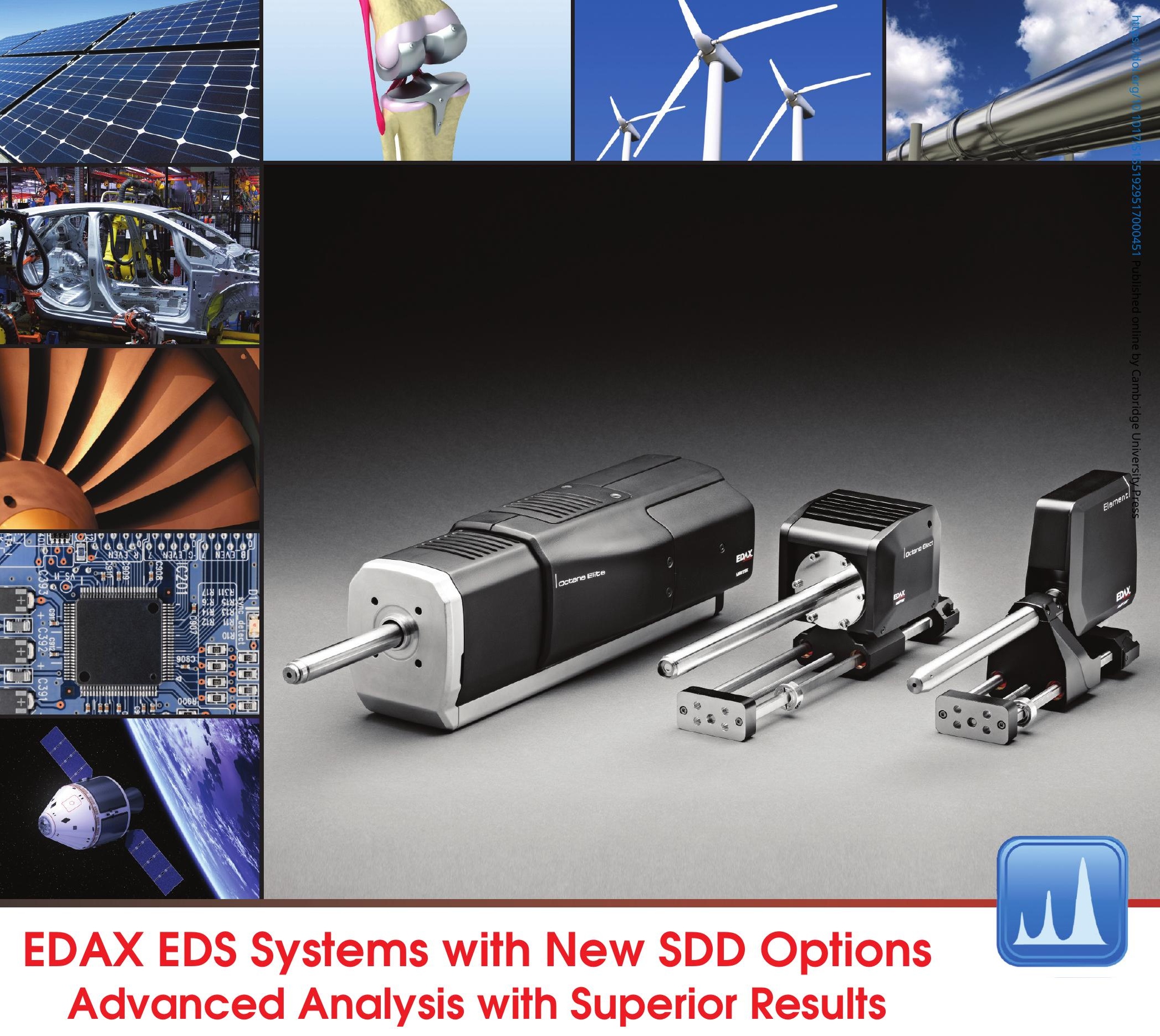

- Choice of optimized SDDs to suit your materials analysis needs

- Best light element sensitivity with silicon nitride $\left(\mathrm{Si}_{3} \mathrm{~N}_{4}\right)$ window

- Vacuum encapsulated module

- Highest throughput SDD available, with unparalleled resolution

- Safe for plasma cleaning 